\title{
Erratum to: Amphibian and reptile communities of rainforest fragments: minimum patch size to support high richness and abundance
}

\author{
Elisa Cabrera-Guzmán • Víctor Hugo Reynoso
}

Published online: 18 September 2012

(C) Springer Science+Business Media B.V. 2012

\section{Erratum to: Biodivers Conserv \\ DOI 10.1007/s10531-012-0312-4}

Unfortunately, some details regarding the statistical tests are not available in the original publication of the article. The complete data is given below. The authors apologize for these mistakes.

\section{Data analysis}

- For PCA the patch size was in ha, $\log _{10}$ transformed.

\section{Results}

Table 1

Kruskal-Wallis d.f. $=7$

- Elevation was compared using the altitude in five selected points across each fragment and reference area; these included the highest and the lowest elevations.

The online version of the original article can be found under doi:10.1007/s10531-012-0312-4.

E. Cabrera-Guzmán · V. H. Reynoso ( $₫)$

Colección Nacional de Anfibios y Reptiles, Departamento de Zoología, Instituto de Biología, Universidad Nacional Autónoma de México, Circuito Exterior, Ciudad Universitaria,

CP 04510 Mexico, DF, Mexico

e-mail: vreynoso@ibiologia.unam.mx

Present Address:

E. Cabrera-Guzmán

School of Biological Sciences, The University of Sydney, Tropical Ecology Research Facility, Middle Point, NT 0836, Australia 
- For vegetation structure the number of Gentry's transects established in every fragment and reference area ranged from five to seven. For consistency we used five randomly selected transects in analyses.

Amphibian and reptile abundance comparison between sites

Both ANOVAs: $F_{7,88}$ 